\title{
Gastric outlet obstruction caused by tuberculosis and diagnosed by endoscopic ultrasound-guided fine needle aspiration
}

A 34-year-old man presented with a 3month history of recurrent episodes of vomiting, anorexia, and weight loss of $16 \mathrm{~kg}$. There was no history of ingestion of nonsteroidal anti-inflammatory drugs and clinical examination was unremarkable. Laboratory investigations revealed hemoglobin of $9.6 \mathrm{~g} / \mathrm{dL}$ (normal range: $12-18 \mathrm{~g} / \mathrm{dL}$ ) with an erythrocyte sedimentation rate (ESR) of $46 \mathrm{~mm} / \mathrm{h}$. Upper gastrointestinal endoscopy revealed an impassable stricture with mucosal ulceration at the junction of the first and second parts of duodenum. An antral biopsy showed Helicobacter pylori, so the patient was started on a proton pump inhibitor (PPI) with antibiotics to eradicate H. pylori. There was no improvement in his symptoms, and repeat endoscopy was performed 4 weeks later, which revealed similar features ( $\bullet$ Fig. 1).

Multiple-site gastric biopsies on this occasion were negative for $H$. pylori and biopsy from the stricture site revealed features of nonspecific chronic inflammation. An endoscopic ultrasound (EUS) was performed, which revealed a markedly thickened duodenal wall with loss of the layered pattern and enlargement of the surrounding lymph nodes ( $\bullet$ Fig. 2 ).

Multiple lymph nodes were also noted at the porta hepatis, celiac axis, and subcarina. EUS-guided fine-needle aspiration (FNA) was performed from the subcarinal and periduodenal lymph nodes ( Fig. 3), and yielded caseous material.

The cytological examination revealed extensive caseating necrosis ( $\bullet$ Fig. 4) and acid-fast bacilli were present ( $\mathbf{F i g}$. 5 ).

The patient was started on four-drug antitubercular therapy, which produced an improvement in his symptoms.

Duodenal tuberculosis accounts for $1 \%-$ $3 \%$ of cases of gastrointestinal tuberculosis $[1,2]$. Tuberculosis is a rare cause of gastric outlet obstruction (GOO), even in developing countries. In one study from India involving 74 patients with GOO, tuberculosis was the cause in only two patients $(2.7 \%)$ [3]. The rarity of duodenal involvement is presumed to be due to the rapid transit time through the duodenum and the complete lack of lymphoid tissue [4]. Tuberculosis may primarily af-

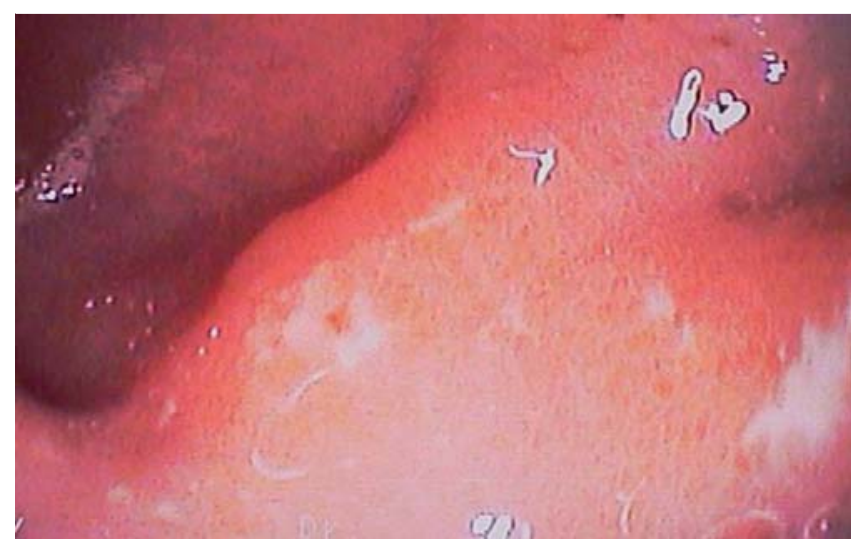

Fig. 1 Impassable stricture with mucosal ulceration at the D1 -2 junction.

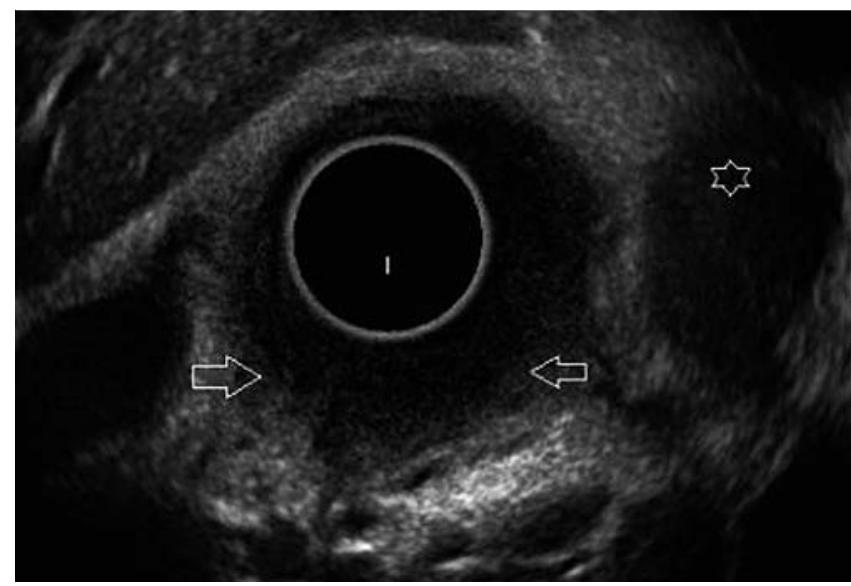

Fig. 2 Radial endoscopic ultrasound (EUS), which shows a markedly thickened duodenal wall with loss of the layered pattern (arrow) and enlargement of the surrounding lymph nodes (star).

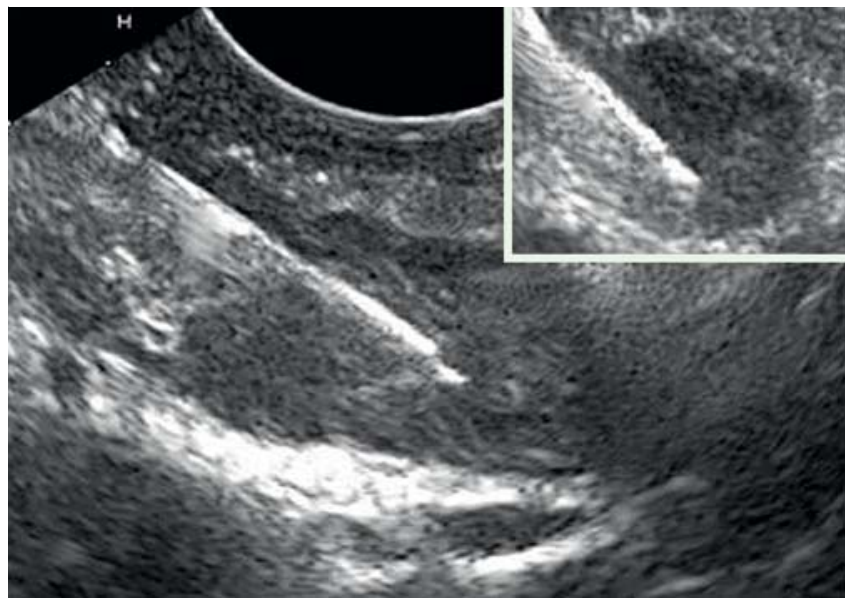

Fig. 3 EUS-fine-needle aspiration (FNA) from the subcarinal and periduodenal lymph nodes (inset).

fect the duodenum by an intrinsic process or by extrinsic compression from lymph nodes. A variety of other duodenal abnormalities, including strictures, ulcers, polypoidal masses, perforations, and fistulas, have been reported in the literature $[1,2,4]$. Nonresponse to PPIs should be an important trigger to consider causes of GOO other than peptic ulcer disease, and in the evaluation of such diagnostic dilemmas, EUS, with or without FNA, may be an important investigation. 

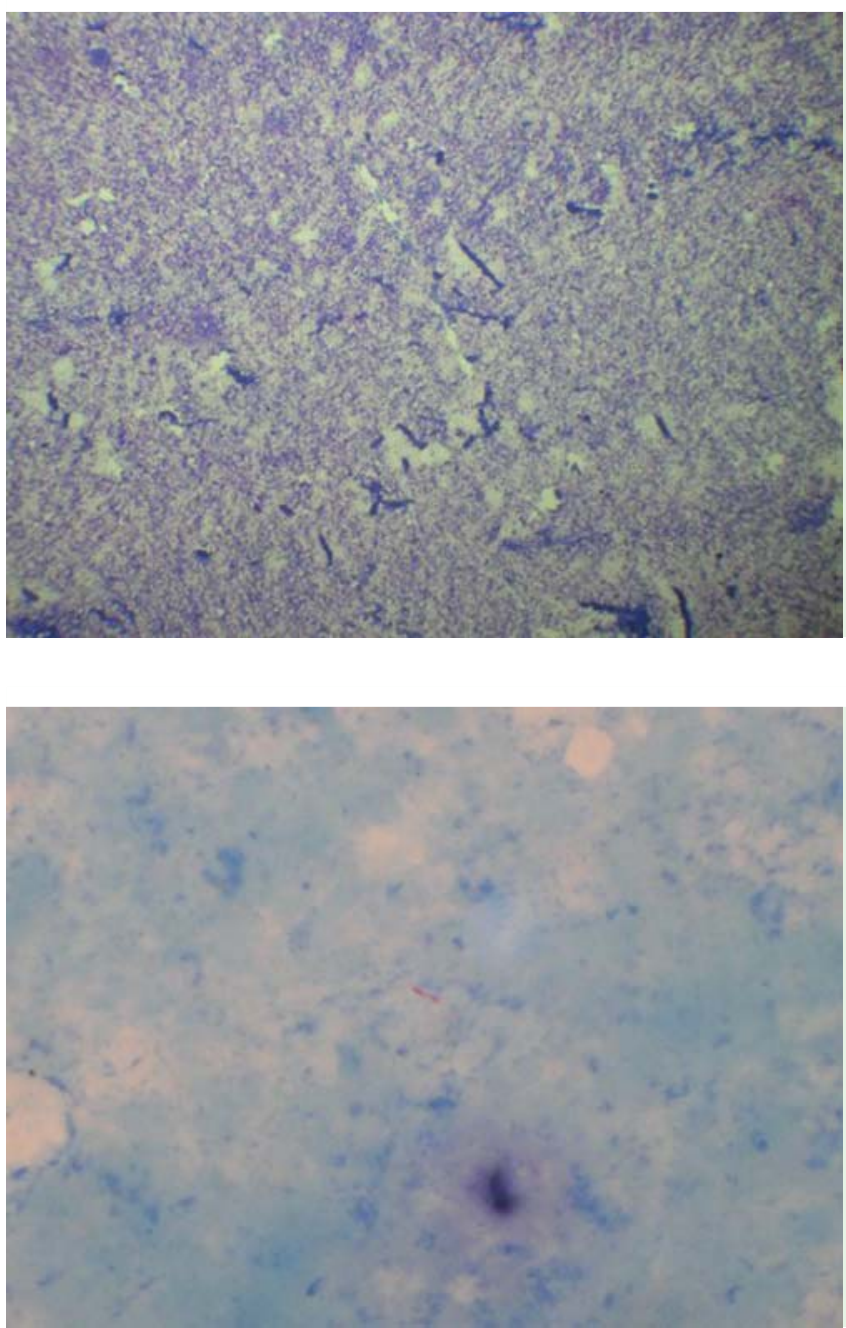

Fig. 4 Extensive caseating necrosis (May-Grunwald Giemsa, × 200).

Endoscopy_UCTN_Code_CCL_1AF_2AD

\section{Competing interests: None}

\section{S. S. Rana', D. K. Bhasin ${ }^{1}$, R. Srinivasan ${ }^{2}$,} K. Singh ${ }^{1}$

${ }^{1}$ Department of Gastroenterology, Post Graduate Institute of Medical Education and Research (PGIMER), Chandigarh, India

2 Department of Cytology, Post Graduate Institute of Medical Education and Research (PGIMER), Chandigarh, India

\section{References}

1 Bhansali SK. Abdominal tuberculosis - experience with 300 cases. Am J Gastroenterol 1977; 67: 324-337

2 Shah P. Gastrointestinal tuberculosis - A review. Indian J Radiol Imaging 1993; 3: 243 251

in the aspirate (ZiehNeelsen, $\times 1000)$.

3 Misra SP, Dwivedi M, Misra V. Malignancy is the most common cause of gastric outlet obstruction even in a developing country. Endoscopy 1998; 30: 484-486

4 Balikian JP, Yenikomshian SM, Jidejian YD. Tuberculosis of the pyloroduodenal area: report of 4 cases. Am J Roentgenol Radium Ther Nucl Med 1967; 101: 414-420

\section{Bibliography}

DOI 10.1055/s-0030-1256144

Endoscopy 2011; 43: E117-E118

(c) Georg Thieme Verlag KG Stuttgart · New York . ISSN 0013-726X

\section{Corresponding author}

\section{S. S. Rana, DM}

Department of Gastroenterology

Post Graduate Institute of Medical Education

and Research (PGIMER)

Sector 12, Chandigarh - 160012, India

Fax: +91-172-2744401

drsurinderrana@yahoo.co.in 